\title{
Lung isolation strategies for repeat video-assisted thoracoscopic surgery (VATS) after major lung resections: a case series
}

\author{
Thirugnanam Agasthian
}

\#14-12 Mt Elizabeth Medical Centre, Mt Elizabeth Hospital, 3 Mt Elizabeth, Singapore

Correspondence to: Thirugnanam Agasthian, MBBS, MMed (Surgery), FRCS (Ed), FRCS (G). Division of Surgical Oncology, National University

Cancer Institute (NCIS), Singapore. Email: t.agasthian@gmail.com.

\begin{abstract}
With increased clinical experience, repeat resections by minimally invasive surgery after previous major resections is becoming more common. In many of these cases due to the extent of previous major resections and limited residual lung capacity, repeat minimally invasive lung surgery is not possible due to inability to tolerate single isolation especially when it is performed on the contralateral side of previous surgery. Though extracorporeal membrane oxygenation (ECMO) can be used to overcome this problem, it increases operative time, technical complexity, costs and risks of major complications. Adoption of cost effective novel selective bronchial blocker techniques in these cases may assist in obtaining safe lung isolation with adequate exposure for minimally invasive surgery to be performed. In this technique the intermediate bronchus was selectively blocked allowing the upper lobe to be ventilated. The use of this technique in four different cases is described. Case 1 patient had previous left lower lobectomy and subsequent right videoassisted thoracoscopic surgery (VATS) lobectomy was possible with right lung isolation by standard double lumen tube due to adequate lung capacity of the residual left upper lobe to tolerate contralateral single lung isolation. Cases 2, 3 and 4 all had prior major lobectomies of the left lung and needed subsequent right VATS major surgery. Case 2 needed a right VATS major decortication for chronic empyema. Cases 3 and 4 needed right VATS lower lobectomy for bronchiectasis and metachronous lung cancer. Case 4 had mediastinoscopy done prior to VATS to mitigate the difficulty of mediastinal lymph node dissection during VATS. In all three cases repeat VATS was done successfully by selective bronchoscopic blockage of the intermediate bronchus by a bronchial blocker allowing for adequate surgical exposure and safe conduct of anaesthesia. All patients had uneventful surgery with no morbidity. Selective lobar isolation with bronchial blocker is a simple cost-effective technique useful in repeat contralateral right VATS surgery without resorting to ECMO or thoracotomy.
\end{abstract}

Keywords: Video-assisted thoracoscopic surgery (VATS); lung isolation; case report

Received: 16 April 2020; Accepted: 09 October 2020; Published: 20 July 2022.

doi: $10.21037 /$ jovs-20-107

View this article at: http://dx.doi.org/10.21037/jovs-20-107

\section{Introduction}

Incidence of repeat video-assisted thoracoscopic surgery (VATS) surgery after previous major chest surgery is uncommon about $1-4 \%$ (1-3). Common indications include new lung primaries, repeat metastasectomy and infective conditions like decortication and bronchiectasis (4).

Clinical considerations before repeat VATS surgery are side of previous surgery (ipsilateral vs. contralateral), extend of previous lung resection, residual lung capacity and in malignancy the size and location of the tumour (peripheral $v s$. central).

Challenges for repeat VATS lobectomy or completion pneumonectomy on the same side as previous resections are usually technical difficulties arising from adhesions and scarring from the previous surgery. Strategies to overcome these technical problems have been reported previously (4-8).

The hallmarks of safe modern thoracic surgery are minimally invasive approach whenever possible in a 
Table 1 Case summaries

\begin{tabular}{|c|c|c|c|c|}
\hline Case & $\begin{array}{l}\text { Previous left lung } \\
\text { pathology/surgery }\end{array}$ & $\begin{array}{l}\text { Present right VATS surgery } \\
\text { and indication for surgery }\end{array}$ & Lung isolation strategy & Outcome and follow-up \\
\hline $\begin{array}{l}\text { Case } 1: \text { male/ } \\
53 \text { years; non- } \\
\text { smoker }\end{array}$ & $\begin{array}{l}\text { Left lower lobectomy for } \\
\text { stage } 1 \text { lung cancer }\end{array}$ & $\begin{array}{l}\text { Right VATS upper lobectomy } \\
\text { for stage } 1 \text { a metachronous } \\
\text { lung cancer }\end{array}$ & $\begin{array}{l}\text { Left sided double lumen } \\
\text { endotracheal tube }\end{array}$ & $\begin{array}{l}\text { Uneventful surgery. In } \\
\text { clinical remission }\end{array}$ \\
\hline $\begin{array}{l}\text { Case } 2 \text { : male/ } \\
45 \text { years; non- } \\
\text { smoker }\end{array}$ & $\begin{array}{l}\text { Stage } 4 \text { metastatic lung } \\
\text { cancer with left collapsed } \\
\text { upper lobe }\end{array}$ & $\begin{array}{l}\text { Right VATS decortication for } \\
\text { chronic empyema }\end{array}$ & $\begin{array}{l}\text { Selective intermediate } \\
\text { bronchus blockage }\end{array}$ & $\begin{array}{l}\text { Uneventful surgery and in } \\
\text { cancer remissions } \\
4 \text { years after surgery }\end{array}$ \\
\hline $\begin{array}{l}\text { Case } 3 \text { : male/ } \\
56 \text { years; non- } \\
\text { smoker }\end{array}$ & $\begin{array}{l}\text { Left upper lobectomy } \\
\text { for TB hemoptysis in } \\
\text { childhood }\end{array}$ & $\begin{array}{l}\text { Right VATS lower lobectomy } \\
\text { for bronchiectasis }\end{array}$ & $\begin{array}{l}\text { Selective intermediate } \\
\text { bronchus blockage }\end{array}$ & $\begin{array}{l}\text { Uneventful surgery. } \\
\text { Discharged from follow-up }\end{array}$ \\
\hline $\begin{array}{l}\text { Case } 4: \text { male/ } \\
65 \text { years; smoker }\end{array}$ & $\begin{array}{l}\text { Left double sleeve } \\
\text { lobectomy for stage } 2 b \\
\text { squamous cell lung cancer }\end{array}$ & $\begin{array}{l}\text { Right VATS lower lobectomy } \\
\text { for metachronous stage } 1 \\
\text { adenocarcinoma }\end{array}$ & $\begin{array}{l}\text { Selective intermediate } \\
\text { bronchus blockage }\end{array}$ & $\begin{array}{l}\text { Uneventful surgery. Lost } \\
\text { to follow-up }\end{array}$ \\
\hline
\end{tabular}

VATS, video-assisted thoracoscopic surgery; TB, tuberculous.

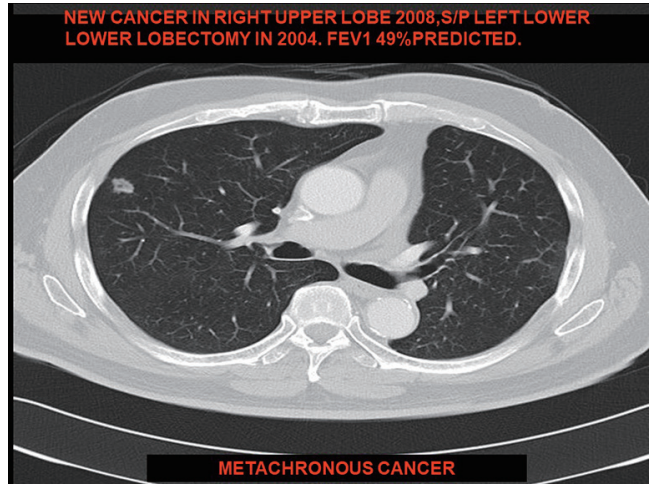

Figure 1 New right upper lobe stage 1 lung adenocarcinoma in a patient with previous left lower lobectomy for stage 1 lung cancer.

completely collapsed lung providing excellent exposure and minimal lung and chest wall trauma. Repeat VATS after previous lung resections have already been proven that it can be done safely by minimally invasive approach (4-8). The technical strategies for single lung isolation during repeat VATS is described. I present the following article in accordance with the CARE reporting checklist (available at https://jovs.amegroups.com/article/view/10.21037/jovs-20$107 / \mathrm{rc})$.

\section{Case presentation (Table 1)}

\section{Case 1}

Case 1 is a 53 -year-old gentleman who had a left lower lobectomy by thoracotomy in 2002 for stage 1 nonsmall cell lung cancer. He was cancer free and on annual surveillance scan in 2015 was noted to have a new right upper lobe primary non-small cell lung cancer. Positron emission tomography-computed tomography (PET-CT) scan showed no evidence of metastases. Despite the previous left lower lobectomy his lung function was normal (Figure 1). He underwent an uneventful right VATS with a standard left-sided double lumen endotracheal tube placed for lung isolation. His residual left upper lobe was of adequate capacity to tolerate contralateral lung isolation (Table 2). Intraoperative ventilation, oxygenation and hemodynamic status were all stable allowing for a safe right VATS upper lobectomy and systematic lymph node dissection to be performed. Post-operative recovery uneventful and he has been well since 2015 with no evidence of cancer recurrence.

\section{Case 2}

A 45-year-old male diagnosed to have stage 4 non-small cell lung cancer with brain metastases, left pleural effusion and complete obstruction of left main bronchus by tumour invasion. He underwent left main bronchial stenting with metallic stents followed by chemotherapy, immunotherapy and radiotherapy to his brain and left hilum. Six months later he developed chronic pseudomonas stage 3 empyema of the right chest due to chemotherapy induced neutropenia and colonisation of the metallic stent. He was septic and breathless due to his immunocompromised state and impaired lung capacity (Figure 2). As his general condition 
Table 2 Normal preoperative lung function despite previous left lower lobectomy

\begin{tabular}{lccc}
\hline Parameter & Best & Predicted & \% predicted \\
\hline FVC (L) & 3.58 & 3.16 & 113 \\
FEV1 (L) & 2.68 & 2.60 & 103 \\
FEV1/FVC (\%) & 74.7 & 78.3 & 95 \\
PEF (L/s) & 6.37 & 7.99 & 80 \\
\hline
\end{tabular}

FVC, forced vital capacity; FEV1, forced expiratory volume in one second; PEF, peak expiratory flow.

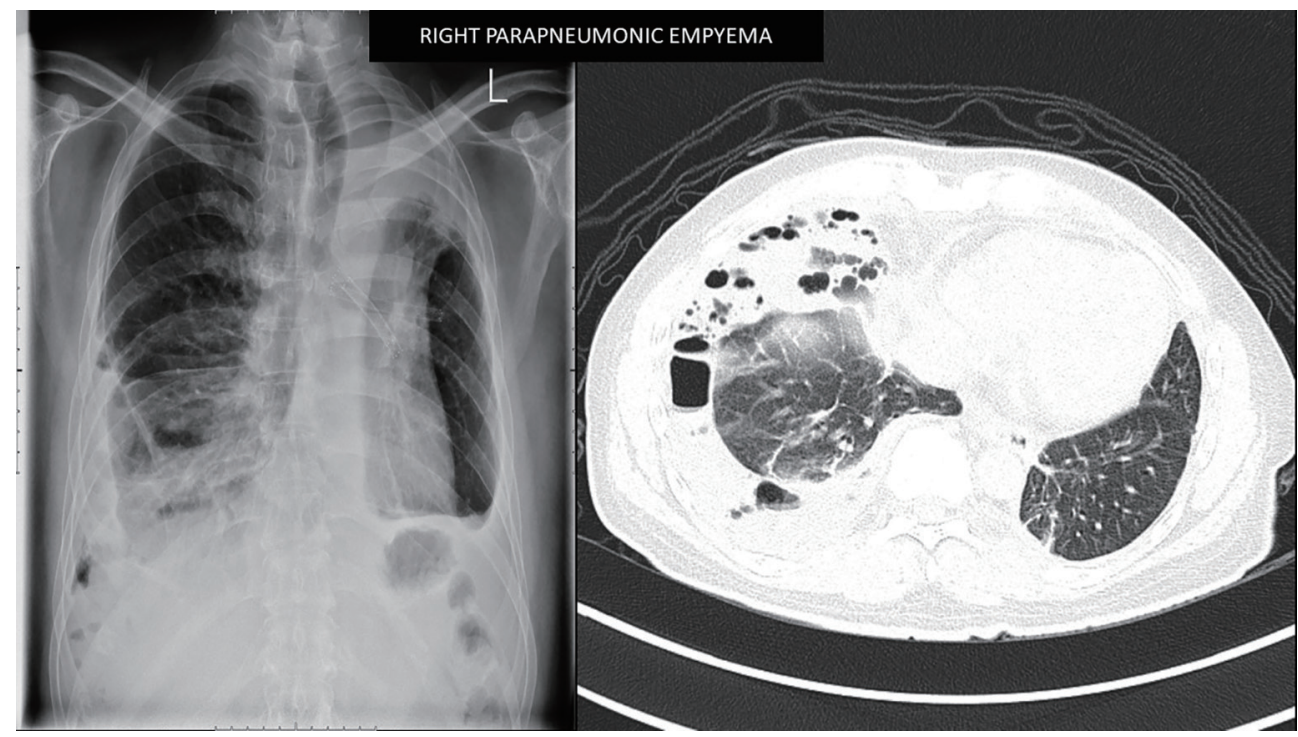

Figure 2 Preoperative chest X-ray and CT scan thorax. CT, computed tomography.

was poor, decision was made to perform decortication by VATS to decrease the morbidity $(9,10)$. Lung isolation was obtained by selective bronchial blockage of the intermediate bronchus to allow ventilation of the right upper lobe bronchus while surgery was conducted by VATS. The selective lobar isolation was obtained by using Arndt blocker endotracheal tube with the blocker introduced into the intermediate bronchus to isolate the lower and middle lobes to be collapsed whilst the upper lobe continues to be ventilated for adequate oxygenation (Figure 3 \& Video 1). This allowed adequate safe oxygenation and exposure for decortication to be performed by VATS (Video 2). The surgical visceral pleural plane in the entrapped lung was better delineated by intermittent inflation of the lung by insufflating oxygen through the blocker channel without deflating the blocker balloon. Post-operative recovery was uneventful and was discharged well with resolution of infection (Figure 4). He was started on immunotherapy with good tumour response. He has remained cancer and infection free 4 years post-surgery.

\section{Case 3}

A 56-year-old male had a left thoracotomy and upper lobectomy in childhood for post-tuberculous hemoptysis. He presented now with recurrent infections from right lower lobe bronchiectasis for 3 years which was initially treated by medical therapy (Figure 5). As the bronchiectasis was limited to one lobe, he was referred for right lower lobectomy and decision was made to do by VATS. Initial intraoperative attempt to isolate right lung by standard left-sided double lumen tube failed due to inability of the left residual lobe to support adequate ventilation and oxygenation. The previously described technique of selective lobar selective lobar isolation technique was used to obtain selective right lung isolation. A right VATS lower 


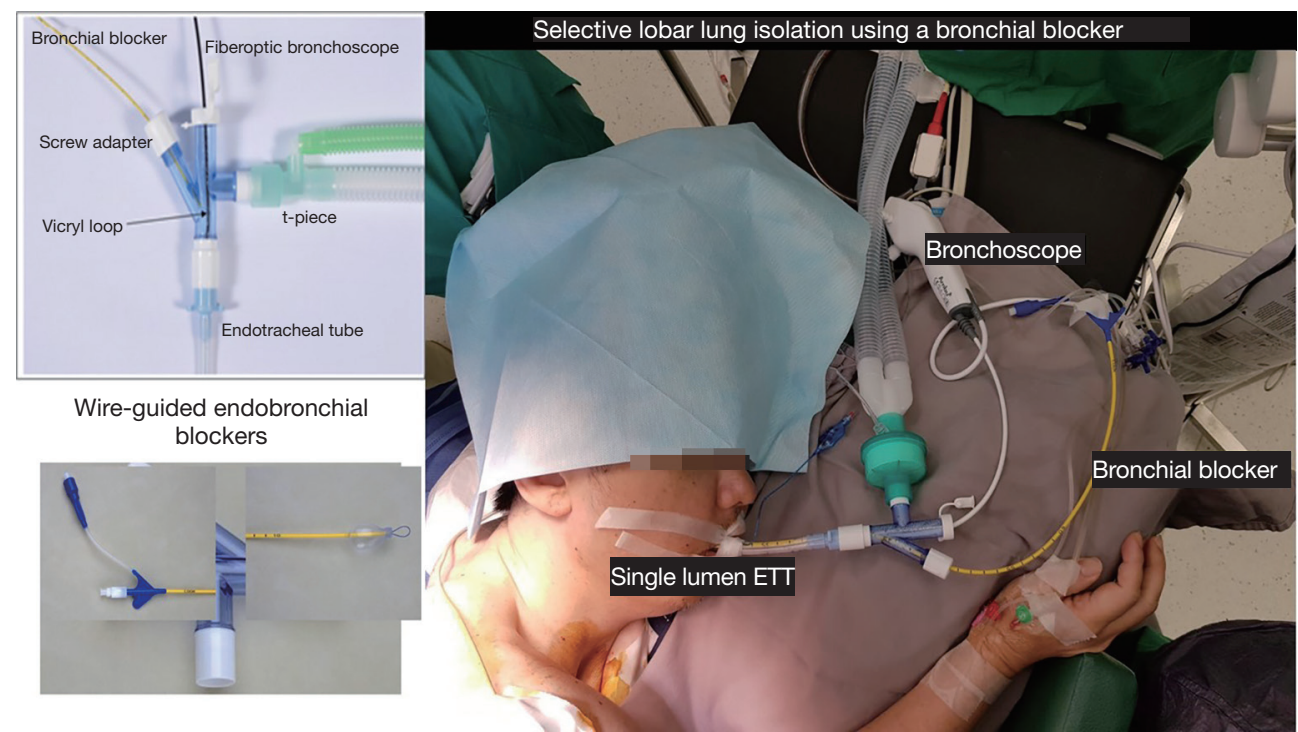

Figure 3 Arndt wire guided endobronchial blocker and tube connector. Written informed consent was obtained from the patients for publication of the image. ETT, endotracheal tube.

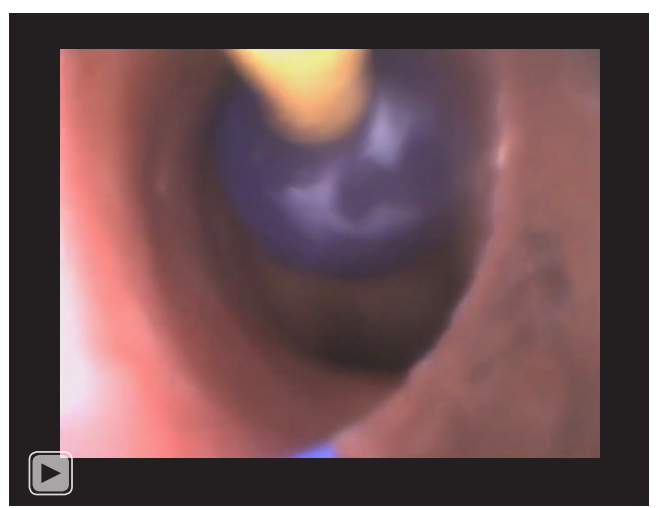

Video 1 Bronchial blocker placement in intermediate bronchus under bronchoscopy guidance.

lobectomy was performed uneventfully without resorting to thoracotomy (Video 3). Post-operative recovery was uneventful and he was discharged well on $4^{\text {th }}$ post-operative day. He has remained well and asymptomatic 13 years after surgery and has been discharged from further follow-up.

\section{Case 4}

A 65-year-old male smoker underwent left thoracotomy and double sleeve upper lobectomy in 2003 for stage 2 non-small cell lung cancer (squamous cell carcinoma). No adjuvant treatment was given. On surveillance scan he developed a

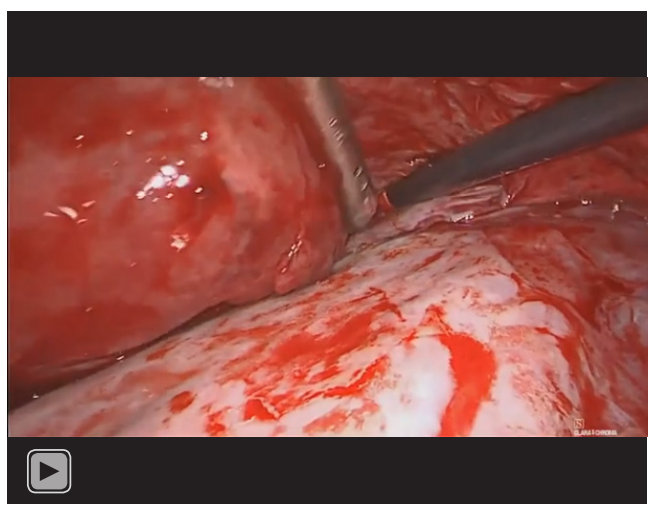

Video 2 Right video-assisted thoracoscopic surgery (VATS) decortication.

new stage 1 metachronous primary lung cancer in the right lower lobe in 2008 which was proven to be adenocarcinoma on CT-guided needle biopsy. PET-CT showed no evidence of metastatic cancer or lymphadenopathy. Preoperative lung function indicated that the left residual lobe would not be able to tolerate single lung ventilation with a standard leftsided double lumen tube. A decision was made to adopt selective right intermediate bronchus isolation technique. In selective lobar isolation the upper lobe continues to be ventilated during VATS making paratracheal lymph node dissection difficult due to limited exposure. Therefore, a mediastinoscopy was performed before VATS for complete 
mediastinal lymph node staging. As all mediastinal lymph nodes sampled were negative for malignancy, he underwent a right VATS lower lobectomy after selective right lobar isolation (Video 4). Intraoperatively only the interlobar and hilar lymph nodes were sampled as the mediastinum was already staged by prior mediastinoscopy. Post-operative recovery was uneventful and was discharged on $3^{\text {rd }}$ postoperative day. He remained cancer free for 4 years and was subsequently lost to follow-up.

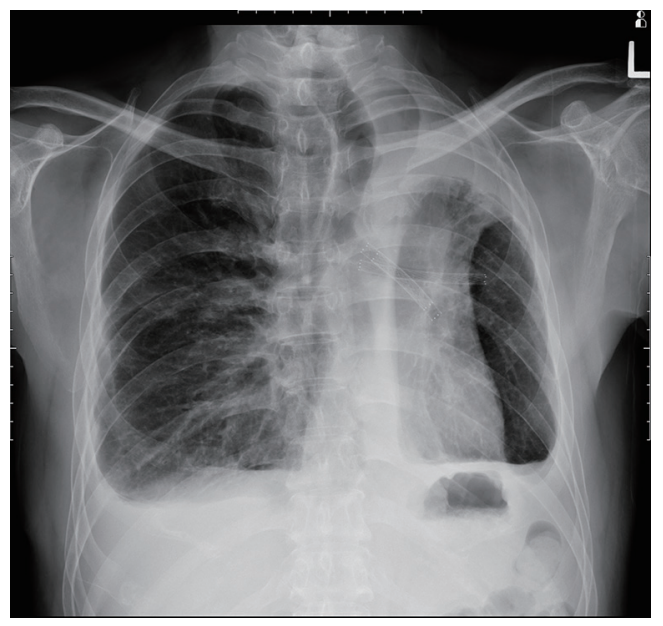

Figure 4 Post-operative chest X-ray.
All procedures performed in this study were in accordance with the ethical standards of the institutional and/or national research committee(s) and with the Helsinki Declaration (as revised in 2013). Written informed consent was obtained from the patients for publication of this case report and accompanying images. A copy of the written consent is available for review by the editorial office of this journal.

\section{Discussion}

With increased clinical experience, repeat resections by

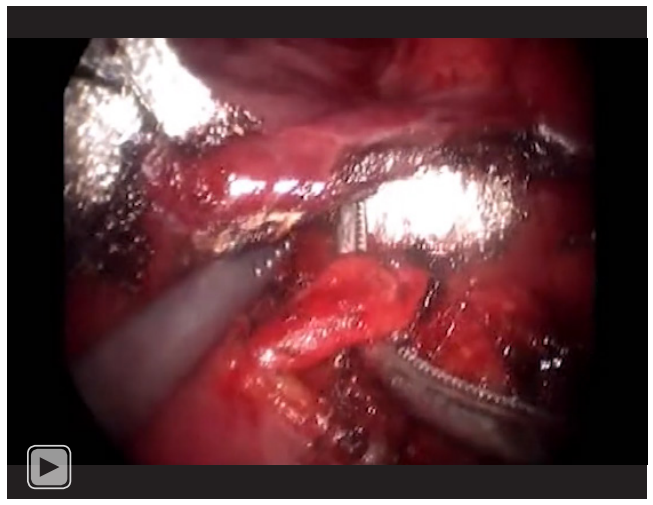

Video 3 Right video-assisted thoracoscopic surgery (VATS) lower lobectomy for bronchiectasis.

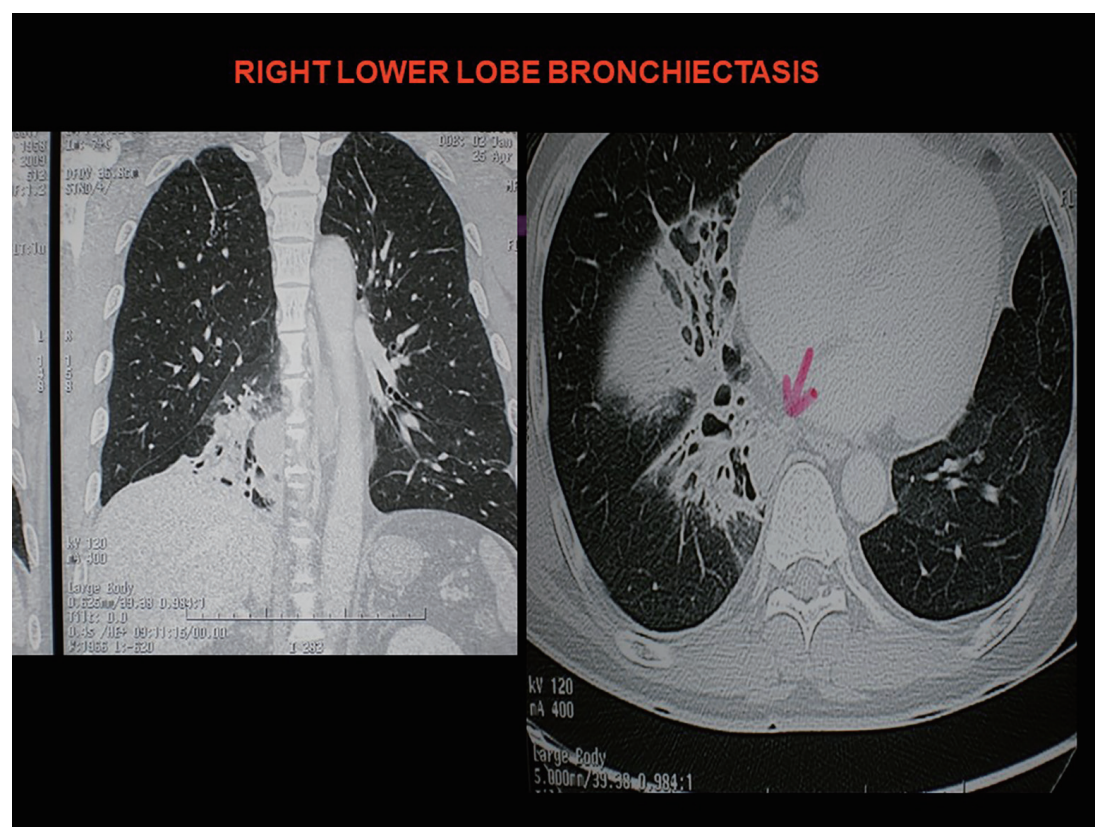

Figure 5 Preoperative chest X-ray of right lower lobe bronchiectasis (arrow) with previous left lower lobectomy. 


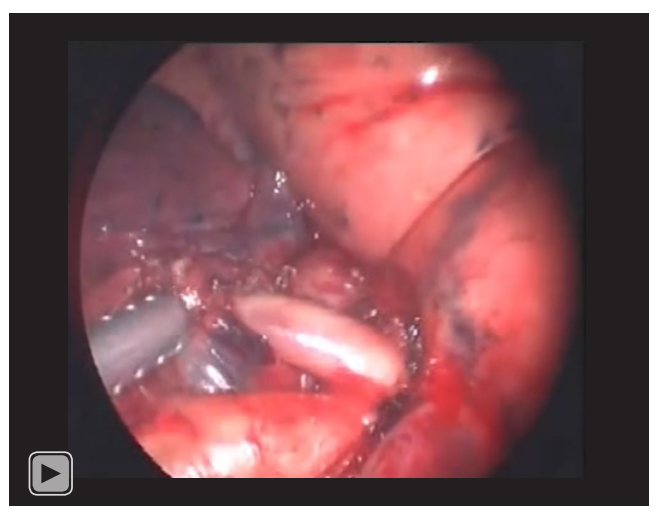

Video 4 Right video-assisted thoracoscopic surgery (VATS) lower lobectomy for recurrent right lung cancer.

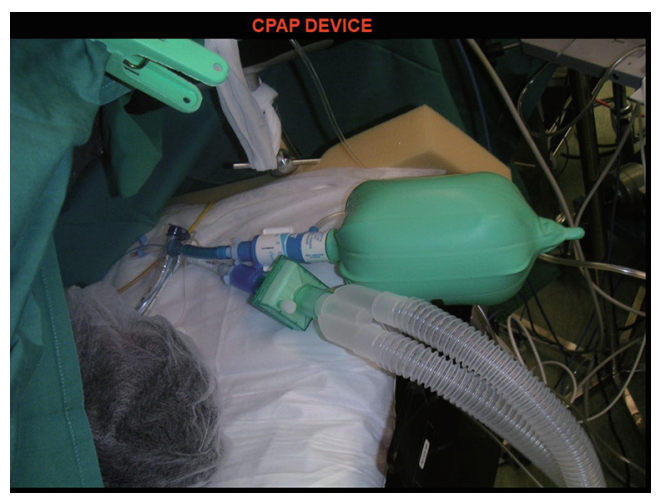

Figure 6 Continuous positive airway pressure (CPAP) applied to the operative collapsed lung.

minimally invasive surgery after previous major resections is becoming more common. Performing repeat surgeries in these cases by VATS though technically more challenging would be ideal as it inflicts less chest wall and lung trauma as compared to thoracotomy with better preservation of lung function. This is important as many of these patients have compromised lung capacity due to previous major lung resections or smoking. VATS also has been shown to have less morbidity and pain with quicker recovery and earlier return to activities. In many of these cases due to the extent of previous major resections with limited residual lung capacity repeat minimally invasive lung surgery is not possible due to inability to tolerate single isolation especially when it is performed on the contralateral side of previous surgery.

For repeat VATS on the opposite side the main consideration is the ability of the previously resected lung side to support single lung ventilation during VATS. This becomes an even greater challenge if the patient has undergone a contralateral bi-lobectomy or pneumonectomy. In many of these situations repeat surgery is done by open thoracotomy with intermittent ventilation and decrease tidal volume with periods of apnoea. This technique impairs the already limited pulmonary reserve due to increased barotrauma and lung contusion from excessive manipulation and retraction in a ventilated lung. Delayed postoperative recovery and morbidity is also higher due to the pain and restrictive effect of thoracotomy on lung function (11-14). This technique becomes even more challenging in deep seated lung lesions where prolonged periods of apnoea are needed.

In patients with previous pneumonectomy, bi-lobectomy or those not able to tolerate single lung isolation, venovenous ECMO allows minimally invasive surgery to be performed safely by providing good exposure in a hemodynamically stable patient. The disadvantages are cost, bleeding, prolong operative time, local technical and systemic complications arising from the insertion and running of the ECMO circuit $(15,16)$. Therefore, less costly, less invasive and simpler lung isolation strategies with less morbidity should be attempted whenever possible before resorting to thoracotomy or ECMO.

Some fit patients with previous major lung resections are able to tolerate single lobe ventilation during contralateral lung isolation due to their excellent residual lung capacity as in case 1. Such instances are rare and applicable only in extremely fit individuals. Most lung cancer patients are elderly smokers with underlying chronic lung disease with compromised lung function where this strategy is inadequate.

In patients with small peripheral lung nodule and inadequate capacity to support full lung isolation, intermittent ventilation with apnoeic spells can be used to do quick VATS wedge resections. In others insufflating oxygen at $2-4 \mathrm{~L} / \mathrm{min}$ which is equivalent to $5-20 \mathrm{~cm}$ water continuous positive airway pressure (CPAP) or a small amount of CPAP (5 to $10 \mathrm{~cm}$ water pressure) applied to the operative side by CPAP device will allow adequate oxygenation and exposure to allow for wedge resections (17) (Figure 6). These measures are usually inadequate for deep seated central lung lesions and clinical conditions requiring prolonged lung collapse.

For right-sided lesions selective lobar isolation of the intermediate bronchus by a bronchial blocker is a useful strategy. It allows adequate exposure and oxygenation for minimally invasive surgery to be performed with the right 


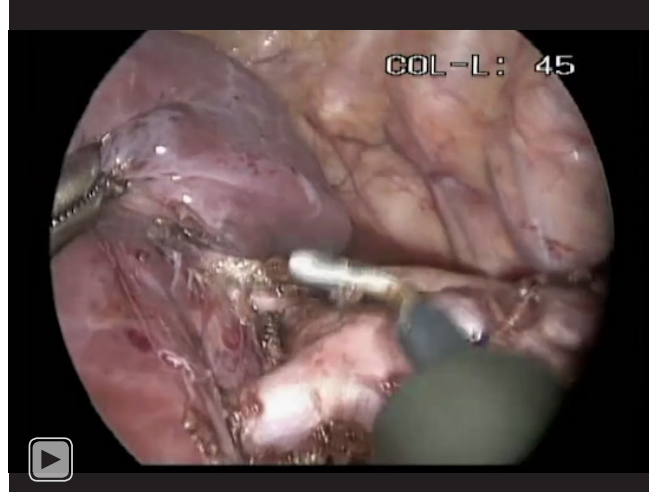

Video 5 Right lung isolation using a Fogarty catheter in a 2-yearold child.

upper lobe being ventilated while the middle and lower lobe are collapsed. The technique allows adequate exposure for simple and complex VATS procedures to be performed for all types of chest pathologies. It is more cost effective than using ECMO or thoracotomy. One limitation with this technique is the ability to perform a complete right radical systematic mediastinal lymph node dissection especially of the paratracheal region due to the limited exposure from the ventilating upper lobe. This can be overcome by performing endobronchial ultrasound (EBUS) of mediastinoscopy before VATS. The other limitation of this strategy is it is only suitable for upper lobe pathologies.

There are many commercially available bronchial blockers (18-20).

(I) Fogarty vascular embolectomy catheter (Edwards Lifesciences, Irvine, CA, USA);

(II) Wiruthan bronchial blocker (Willy Rusch AG, Kernen, Germany);

(III) Single-lumen endotracheal tube with an enclosed bronchial blocker (Torque Control Blocker Univent Vitaid Lewinston, NY, USA);

(IV) Wire-guided endobronchial blocker (Arndt blocker; Cook Critical Care, Bloomington, IN, USA).

Preference is for the Arndt blocker due to it's the spherical balloon cuff which provides a better seal for right main bronchus and selective lobar blockades. Elliptically shaped cuffs are better for left main bronchus isolation as its elongated shape fits better into the left bronchus (18).

The Arndt blocker is a single unit with 3 working channels which is passed through a single-lumen endotracheal tube. The single lumen tube has three separate channels one each for a wire-guided endobronchial blocker, bronchoscope and ventilation (18). It can be used for patients up to 6 years old below which best to use a Fogarty catheter (Video 5).

Before insertion, the blocker balloon is tested then fully deflated. It should be lubricated with silicone spray or lubricating jelly. The blocker port should be fully opened before insertion of the balloon to prevent damage to the blocker cuff. The placement of the blocker is done with the wire-guide loop snared around the bronchoscope and together guided into the bronchus. The bronchoscope has to be advanced far enough so that the blocker will enter the bronchus while it is being advanced. Once the deflated cuff is below the entrance of the bronchus, the bronchoscope is withdrawn. The optimal position of the blocker is achieved when the blocker balloon outer surface is seen with the bronchoscope at least $5 \mathrm{~mm}$ below the carina. To prevent dislodgment during patient positioning the deflated blocker should be advanced $1 \mathrm{~cm}$ in the supine position with bronchoscopic confirmation again in the lateral decubitus position. The blocker is then locked in position to prevent dislodgement by tightening the crew adapter. A proper seal is obtained by inflating the cuff with $2-3 \mathrm{~mL}$ of air for selective lobar blockade and $5-8 \mathrm{~mL}$ of air for total bronchial blockade. A good seal can also be obtained by attaching a $\mathrm{CO}_{2}$ analyser to the proximal end of the blocker and noting when the waveform disappears. The wire-loop can then be withdrawn to convert the 1.4-mm channel into a suction port to expedite lung collapse and suction of retained secretions. It is also important to remove the guide wire-loop to avoid inadvertent inclusion during stapling of the bronchus (21).

\section{Conclusions}

Repeat VATS surgery after previous major surgeries can be challenging due to inability to obtain adequate single lung ventilation safely. By selective adoption of cost-effective novel strategists like CPAP and selective bronchial blocker techniques repeat minimally invasive surgery can be done safely thus avoiding thoracotomy or ECMO.

\section{Acknowledgments}

Funding: None.

\section{Footnote}

Reporting Checklist: The author has completed the CARE 
reporting checklist. Available at https://jovs.amegroups. com/article/view/10.21037/jovs-20-107/rc

Conflicts of Interest: The author has completed the ICMJE uniform disclosure form (available at https://jovs. amegroups.com/article/view/10.21037/jovs-20-107/coif). TA serves as an unpaid editorial board member of fournal of Visualized Surgery from June 2019 to May 2021.

Ethical Statement: The author is accountable for all aspects of the work in ensuring that questions related to the accuracy or integrity of any part of the work are appropriately investigated and resolved. All procedures performed in this study were in accordance with the ethical standards of the institutional and/or national research committee(s) and with the Helsinki Declaration (as revised in 2013). Written informed consent was obtained from the patients for publication of this case report and accompanying images. A copy of the written consent is available for review by the editorial office of this journal.

Open Access Statement: This is an Open Access article distributed in accordance with the Creative Commons Attribution-NonCommercial-NoDerivs 4.0 International License (CC BY-NC-ND 4.0), which permits the noncommercial replication and distribution of the article with the strict proviso that no changes or edits are made and the original work is properly cited (including links to both the formal publication through the relevant DOI and the license). See: https://creativecommons.org/ licenses/by-nc-nd/4.0/.

\section{References}

1. Deschamps C, Pairolero PC, Trastek VF, et al. Multiple primary lung cancers. Results of surgical treatment. J Thorac Cardiovasc Surg 1990;99:769-77; discussion 777-8.

2. Ishigaki T, Yoshimasu T, Oura S, et al. Surgical treatment for metachronous second primary lung cancer after radical resection of primary lung cancer. Ann Thorac Cardiovasc Surg 2013;19:341-4.

3. Yang H, Sun Y, Yao F, et al. Surgical Therapy for Bilateral Multiple Primary Lung Cancer. Ann Thorac Surg 2016;101:1145-52.

4. Agasthian T. Repeat VATS major resection after previous lobectomies. National University Hospital, Singapore, Poster 93 ISMICS meeting, Thoracic Track, Los Angeles,
2012.

5. Agasthian T. VATS middle lobectomy following a previous right VATS lower lobectomy. CTSNET Thoracic Video, Oct 24, 2011.

6. Agasthian T. Right video-assisted thoracoscopic completion pneumonectomy. Interact Cardiovasc Thorac Surg 2015;21:S42.

7. Agasthian T. Right VATS completion pneumonectomy. Nov 17, 2016. ESTS you-tube channel.

8. Agasthian T. Right VATS completion pneumonectomy. CTSNET Thoracic Video, Feb 5, 2011.

9. Chan DT, Sihoe AD, Chan S, et al. Surgical treatment for empyema thoracis: is video-assisted thoracic surgery "better" than thoracotomy? Ann Thorac Surg 2007;84:225-31.

10. Tong BC, Hanna J, Toloza EM, et al. Outcomes of videoassisted thoracoscopic decortication. Ann Thorac Surg 2010;89:220-5.

11. Cerfolio RJ, Allen MS, Trastek VF, et al. Lung resection in patients with compromised pulmonary function. Ann Thorac Surg 1996;62:348-51.

12. Grodzki T, Alchimowicz J, Kozak A, et al. Additional pulmonary resections after pneumonectomy: actual longterm survival and functional results. Eur J Cardiothorac Surg 2008;34:493-8.

13. Ayub A, Rehmani SS, Al-Ayoubi AM, et al. Pulmonary Resection for Second Lung Cancer After Pneumonectomy: A Population-Based Study. Ann Thorac Surg 2017;104:1131-7.

14. Donington JS, Miller DL, Rowland CC, et al. Subsequent pulmonary resection for bronchogenic carcinoma after pneumonectomy. Ann Thorac Surg 2002;74:154-8.

15. McRae K, de Perrot M. Principles and indications of extracorporeal life support in general thoracic surgery. J Thorac Dis 2018;10:S931-46.

16. Redwan B, Ziegeler S, Freermann S, et al. Intraoperative veno-venous extracorporeal lung support in thoracic surgery: a single-centre experience. Interact Cardiovasc Thorac Surg 2015;21:766-72.

17. Benumof JL, Gaughan S, Ozaki GT. Operative lung constant positive airway pressure with the Univent bronchial blocker tube. Anesth Analg 1992;74:406-10.

18. Campos JH. An update on bronchial blockers during lung separation techniques in adults. Anesth Analg 2003;97:1266-74. Erratum in: Anesth Analg 2004;98:131.

19. Narayanaswamy M, McRae K, Slinger P, et al. Choosing a lung isolation device for thoracic surgery: a randomized 
trial of three bronchial blockers versus double-lumen tubes. Anesth Analg 2009;108:1097-101.

20. Cohen E. Back to blockers?: the continued search for the ideal endobronchial blocker. Anesthesiology

doi: 10.21037 /jovs-20-107

Cite this article as: Agasthian T. Lung isolation strategies for repeat video-assisted thoracoscopic surgery (VATS) after major lung resections: a case series. J Vis Surg 2022;8:31.
2013;118:490-3.

21. Yeoh TY, Ng ES, Agasthian T, et al. Lung Injury From Use of a Suction Catheter via the Double-Lumen Tube. J Cardiothorac Vasc Anesth 2015;29:1618-20. 